\title{
The sensor technologies for more efficient cow reproduction systems
}

\begin{abstract}
Good reproduction is key for successful dairy farming. Detection of estrus is the first step in getting a cow pregnant. Inadequate and inaccurate estrus detection is frequently a cause of cows becoming repeat breeders. Sensor technologies are being used to monitor the production and physiological condition of the animals. Increasingly, these innovations are leading to a more efficient performance of dairy cows, in terms of both physiology and profitability. Three types of sensors used in this area; electrochemical sensors, chemoresistive gas sensors chemoresistive sensor. Chemoresistive gas sensors have received impulse great deal of attention because of its many advantages over other sensing technologies. Electrochemical sensors are becoming unpopular as they have a short lifetime, rendering them unacceptable for some applications. Optical sensors show excellent characteristics of sensitivity, selectivity, adequate lifetime, and fast response; however, they have a high cost and large size. A chemoresistive sensor is based on a sensitive material, in bulk or deposited on a suitable support, upon which the molecular recognition process takes place. Classical Taguchi sensors have a sensitive material in the form of sintered porous ceramic body. Planar-type gas sensors are constituted of a sensing thick/thin layer deposited by chemical or physical methods onto a ceramic substrate with interdigited electrodes. Sensing nanomaterials may be quite unstable under thermal conditions due to their high surface energy leading to severe grain growth, which may result in the degradation of the device performances. Under such operations, the mechanical deterioration of electrodes can also lead to performance degradation due to the possible formation of microcracks on the electrode structure. Therefore, the development of novel sensors with higher sensitivities is the goal of much recent research efforts. This paper will give an overview of the commercial sensor-based devices that are currently available in market.
\end{abstract}

Keywords: reproduction, cattle, novel sensors, device, estrus detection, smart agricultural production
Volume 4 Issue 3 - 2019

\author{
Serap Göncü, Nazan Koluman \\ Department of Animal Science, Faculty of Agriculture, Çukurova \\ University, Adana-Turkey
}

\begin{abstract}
Correspondence: Serap Göncü, Department of Animal Science, Faculty of Agriculture, Çukurova University, AdanaTurkey, Tel 905333606282, Fax 903223386576 Email sgoncu@cu.edu.tr, Serapgoncu66@gmail.com
\end{abstract}

Received: May 31, 2019 | Published: June 24, 2019

\section{Introduction}

Cow functional fertility detection technologies are the latest critical research area for effective cow reproduction management. Dairy farm cow milk yield is increasing while fertilization rate is getting decrease. Cow estrus detection has many difficulties because of many reason. Oestrus detection generally depends on behavioral changes of cows such as standing, mounting, walking, restlessness, chin pressing. Traditional, oestrus detection method is visual observation. But observation method is not applicable on large dairy farms because of high labour and low efficiency. Technological aids are heat mount detectors, radio telemetric devices, mount count devices, sensors and pedometers. The technological developments and the adoption of automation have also become widespread. The technological developments and the adoption of automation have also become widespread on dairy herd reproductive monitoring systems. Many oestrus detection devices have been developed to assist farmers in detecting oestrus and determining the optimal insemination time. The results of oestrus detection methods are variable but technologic observation gives more advantageous results in general to the farmers. Electronic systems are devices that perceived, monitored and recorded one or two oestrus behavior for convenient results of computerized estrus detection devices. ${ }^{1}$ Cow mounting activity detected using patches. These patches are put on the cow 18 days after calving and control just color change for oestrus. Some of these patches send a signal to a receiver which contains date, time and duration of mounting activity. All this signals evaluated by computer programs and prepared for final decision report. But efficiency varies depending on many other factors such as cow number, barn type, and statistical data analysis method. The error rates of these methods vary between $1 \%-55 \%$ and false warnings are also high level. ${ }^{2}$ But oestrus detection error gives farmers big economic loses which vary \$2-\$6/day. Prevention of these losses is possible using technologic detection aids. ${ }^{1}$ Roche ${ }^{3}$ reported that the high yielding lactating cows produced more milk ( $\geq 40 \mathrm{~kg} / \mathrm{day})$; had short oestrus duration $(6.2 \pm 0.5 \mathrm{~h}$ versus $10.9 \pm 0.7 \mathrm{~h})$; less mounting activity $(6.3 \pm 0.4$ versus $8.8 \pm 0.6)$ and short standing duration $(21.7 \pm 1.9 \mathrm{~h}$ versus $28.2 \pm 1.9 \mathrm{~h})$ than lower producing cows measured at the same conditions. The reproductive performances of the farms can be determine and compare using calving interwal values which is ideal values is 13 and 18 months. ${ }^{4,5}$ This period generally longer than ideal values because of many reason. But main factor generally accepted heat detection success. Heat detection success values reported that $30 \%$ and $50 \%$ for most dairy herds. ${ }^{6,7}$ Research results showed that the $5-30 \%$ of the cows were not in or near oestrus when inseminated. ${ }^{8,9}$ Significant factors reported herd size, milk yield, calving age, lactation number, and calving interval $(\mathrm{P}<0.01)$ Interestingly small size farms has more acceptable reproductive performance values. ${ }^{10}$ Mean duration of oestrus was calculated by Schofield et al. ${ }^{11}$ as $13.5 \mathrm{~h}$ with a standard deviation of $2.3 \mathrm{~h} .{ }^{12,13}$ Roelofs et al. ${ }^{14}$ reported that $90 \%$ of cows in estrus showed mounting behavior, but only $58 \%$ of cows showed 
standing behavior. Sector searching new smart technologic aids for improving reproduction performances in cattle production. In the market many technologic aids are available to meet farmer heat detection requirements which different characteristics and price. ${ }^{15}$ Although the costs of computerized systems are higher than technical applications other methods, they pay off with increased conception rate. This article has been review to summarize the characteristics of sensor-based devices in the detection of oestrus as a solution to farmers in the market.

\section{Sensor technologies}

Many technologic aids are available on market to meet farmer cow heat detection at farm level which different characteristics and price. The main advantage of these systems is due to the opportunity of combining the logic and ease of the farmer's needs for oestrus detection.

Oestrus, which is an indication that cows are ready to insemination, may take six to thirty hours with oestrus specific behaviors. The optimum insemination time is to 24 to $12 \mathrm{~h}$ before ovulation. ${ }^{16}$ Heat detection requires accurate determination of oestrus specific behavior and parameters. Many behavior of cow (lying, standing, idle time eating, drinking) changes during oestrus period. And this changes used for many technologic aids for estimation of ovulation time, animal welfare and many other purposes. ${ }^{17}$ Heat detection requires accurate monitoring of physiological behavior patterns and parameters. Increasingly, these innovations are leading to a more efficient performance of dairy cows, in terms of both physiology and profitability. Three types of sensors used in this area; electrochemical sensors, chemoresistive gas sensors chemoresistive sensor. Chemoresistive gas sensors have many advantages such as simplicity; low cost, small size and ability to integrate into electronic devices over other detection technologies. ${ }^{18}$ Electrochemical sensors are becoming unpopular because of high cost and large size. A chemoresistive sensor based on molecular recognition process which is very sensitive but not selective. Sensors were developed for better and accurate automation of oestrus detection system. There are several solid-state gas sensors currently available for gases such as Taguchi sensors. Taguchi sensors have a sensitive material in the form of sintered porous ceramic body. Planar-type gas sensors are constituted of a sensing thick/thin layer deposited by chemical or physical methods onto a ceramic substrate with interdigital electrodes. ${ }^{18}$ Thermal conditions effect sensor result due to their high surface energy leading to severe grain growth, which may result in the degradation of the device performances. The formation of micro-cracks on the electrode structurecan also leads to performance degradation. The very low level target gas concentrations can detect using sensors and determine the markers and the target gas is to be analyzed and quantified. ${ }^{18}$

\section{Standing activity}

Mounting and standing to be mounted activity is the main behavioral criterai for oestrus detection. Hormonal level changes affect cow behavior before especially 3 days before oestrus. Cow showed different behavioral pattern during this days. Oestradiol level during the preovulatory follicular phase effect cow physical and mounting activity. Oestradiol can be monitored in various ways. Roelofs et al. ${ }^{19}$ report that only $58 \%$ of heat cows which detected pressure sensors are accurate time for conception. On the market there are systems that give standing cow list. Many system colect many data about cow which generally cows number, standing activity, number and duration, frequency, date and hour. ${ }^{15}$

\section{Mounting activity}

Mounting is the sign of start of oestrus period. Because of this many system developed for detect early oestrus detection for obtain better pregnancy rate. Many mounting behavior detection systems are available in the market, but the results are not enough for a successful cow pregnancy rate. For this point of view this tool needs of automation system support for better results. The another effective oestrus detection methods is a marker or teaser animal which worn marking device. The use of the teaser bull was associated with a reduction in the incidence of silent heats $(6.4 \mathrm{v} 10.8 \%)$. The differences between the groups aspect of oestrus the results showed that teaser bull usage is very effective. ${ }^{20}$ One more advantages of teaser bull are to provoke oestrus by pheromones. Teaser bull mounted of heat cow the chin-ball marker leave a sign on her back. The effective methods for estrus detection are mainly mounting and standing activity. Using these parameters when the animal is in standing estrus, the detector will send a radio signal to computer and prepare heat cow list. Electronic mounting activity detectors placed on animal tail head and recorded activity.

\section{Walking activity}

Cattle breeds have different walking speed and many factors affect their walking speed. Especially docility of the animal, flooring system, barn lighting and hoof health is very important factor of their walking speed. The cow foot health indicators can be regarded as foot placement, length of stride, step and walking speed. During estrus period cow step number and walking speed increased. ${ }^{21}$ Because of this walking speed today used for heat detection..$^{22}$ Step number and walking speed counter can be used for leg or neck. Each of system continuously record animal behavior and activity and send data for a 2 to $5 \mathrm{~km}$ far away. One collar sensor can be used multiple times. But recent research a more secure method of attaching transmitters to the $\operatorname{cows}^{23}$ to keep sensor transmitter's maintenance difficulties. Pedometers can be described as step counter which is place on cow leg. This pedometer count step number per hour during oestrus depending on the many hormonal changes. Pedometer stored all physical activity of the cows and sudden changes reported that the system for control. Before result report animal current physical activity compared previous behavioral pattern. After analyzing behavioral pattern of cow programs report heat cows list. Pedometer results can be given computer; beeper of flushing to the farmer for control this cows ${ }^{15}$ The lower pedometer reading can be obtain because of parity, milk production, insemination during the warm period. ${ }^{22}$ The cow fertility and walking activity corelations is determined using statistical methods. Pregnancy rate were not affected by herd, milk production, estrous synchronization, lactation stage, and inseminator. But generally cow and management factors directly affect walking activity at estrus which is closely link to fertility.

\section{Restlessnes}

Oestrus is the period which a cow shows specific behaviour to oestrus, which is accepted right time to insemination. Most of these cows showed only one of the known oestrus behaviours. Heat cows show more restless and alert to their environment, interact with other cattle. Research Show that heat cows spend more restlessness time than non estrousherd mates. A new a wireless network with acceleration 
sensor methods reported for detecting estrus by Watanabe et al. ${ }^{24}$ It depends cow restlessness behaviour. But there is a conflict because of mosquitoes, flies and horse-flies, and this method corrected results by taken into this factor also. Restlessness also affected social hierarchy, season, stress conditions, housing, floor surface, yield, lameness and number of herd mates in oestrus simultaneously. ${ }^{25}$

\section{Vocalization}

Cattle vocalization generally can categorize two different states as hungry and weaning state. But researchers try to recognition estrus specific voice of cows. Vocalization can be suggested as oestrus signal for remote sensing techniques. ${ }^{26,27}$ Vocalizations provide important information about animal what isage, sex, dominance and physiologic stage of the cow. In the herd calves recognized mothers their voice. Cattle may bellow more frequently during estrus. But generally this signs not accepted as a definitive signs of heat. Chung et al. ${ }^{28}$ propose the new solution for the detection of oestrus, using the sound data. They reported that voice identification can be indicator of estrus economic and accurately. Their results showed that mel frequency cepstrum coefficients from sound data with a feature dimension reduction, and use the support vector data description as an early anomaly detector. There are few studies on this issue and there is still more space among new topics.

\section{Odour}

The electronic nose is to mimic of smell sense of cow. Evaluating the volatile components emitted from biological materials, electronic nose systems that determine their various characteristics are used in many areas such as food sector, environmental control and human health. ${ }^{29}$ An electronic nose system for determining different properties. A number of research groups worked on devices that mimic the biological olfactory system. ${ }^{30}$ It consists of sensors, signal acquisition unit and sample identification software. Commercially available items are available, but are costly and difficult to use. Therefore, the development of more economical and simple systems is necessary. Many body fluids can be used for oestrusphremeons, volatile fatty acids i.e., Acetic acid (AA), Propionic acid (PA) and 1iodoundecane. ${ }^{31}$ The odour is not emitted by vaginal mucus or urine was also reported). The pheromones are actually released by the dung of cow in estrus. Dogs were used for oestrus detection odour correctly in approximately 80 percent of estrus cow. Dog can detect estrus by urine and milk, after being trained with vaginal fluid samples ${ }^{32}$ and isolated later in feces estrous cow. ${ }^{31}$ Different types of sensors are used in electronic nose systems. Most of these are metal-oxide semiconductors, modified metal-oxide semiconductors, conductive polymers, and conductive oligomers. When these sensors are exposed to odor, their electrical conductivity varies due to oxidation or swelling. Therefore, this change in conductivity affects the voltage value passing through the sensor.

Different odors cause different responses in the sensors, and these responses provide a signal pattern characteristic of a particular aroma. The computer evaluates the signal pattern and can compare the aromas of different samples, using pattern recognition. The instrument consists of an array of gas sensors with different selectivity patterns, a signal collecting unit, and data analysis software, which analyses the signal by pattern-recognition methods, such as principal component analysis, discriminate function analysis, cluster analysis, and artificial neural networks. ${ }^{31}$

\section{Body temperature}

Temperature measurements as well as daily life, production, industry and industry is one of the most necessary measurements. The most critical point of many processes is the need to have a certain level of temperature and continuous control. Different temperature sensors are used for different needs. The type and nature of the sensor to be used will vary due to the measurement environment, temperature measurement value ranges, measurement accuracy.

For calving time detection and cows health monitoring can be measured with radio telemetric transmission.

Some of them produced as aingested type as a bolus and measure the temperature in the reticulum and the vagina. Fisher et al. (2008) measured the vaginal temperature of 21 induced oestrus in 12 non lactating Holstein cows and reported a mean temperature increase of $0.48^{\circ} \mathrm{C}$ at the time of the $\mathrm{LH}$ peak. But some other factors such as outside temperature, disease also increased body temperature which can increase false positives alert. There are very few studies on electronic nose cattle pheromones and still need more research results at field conditions.

\section{Chemical sensors}

Sensors measuring the amount of condensation, content, oxidation/ proofing, reaction rate, $\mathrm{pH}$ are called chemical sensors. These are work routinely as a inline part of the system and measure metabolites and $\mathrm{P} 4$ concentration in milk. ${ }^{19}$ This technology can be completely overlooked because of rapid change at the oetsrusmoment as intermittent measurements are made, although theoretically correct. ${ }^{33}$ But there are many other body fluid is also studied such as cervical mucus, vaginal characteristics, temperature, blood, and hormonal changes during oestrus. Milk progesterone level is o good criteria which isused for diagnose problem cows in herd. , $34-37^{-37}$

\section{Results}

In the last 10 years, smart animal tracking technology has become much cheaper, economical, and functional. The size of the tools used in this technology has become smaller and more useful for the farm level. Researcher reported that only $58 \%$ of cows were observed in standing oestrus. And the pregnancy rate mean sustainably and profitable cattle production. Smart technologies are being to use animal husbandry. Sensor technologies newly used for cattle production management. These innovative applications are leading to a more efficient cow management in terms of both physiology and sustainability. Multi disciplinary contributions provide novel, smaller, integrated, high performance and reliable devices for advanced farm applications. But there are very few studies on sensor technologies on cattle productions. There is still need more research which carried out multidisciplinary.

\section{Acknowledgments}

None.

\section{Conflicts of interest}

The authors declared there is no conflict of interest.

\section{References}

1. Perry JA. Comparison of the efficiency and accuracy of three estrous detection methods to indicate ovulation in beef cattle. 2005 . 
2. Eradus WJ, Rossing PH, Hogewerf E, et al. Signal processing of activity data for oestrus detection in dairy cattle. In: Ipema, Lippus, Metz, Rossing, editors. Proceedings of the International Symposium on Prospects for Automatic Milking. Wageningen, The Netherlands: Pudoc Scientific; 1992:360-369.

3. Roche JF. The effect of nutritional management of the dairy cow on reproductive efficiency. Anim Reprod Sci. 2006;96(3-4):282-296.

4. Üçeş H, Karakök GS. The reproductive performance of holsteinfriesian cattle which kept intensive dairy unit located Çukurova region. ÇÜZF Dergisi. 2007;22(1):1-10.

5. Bakır G, Kaygısız A, Yener SM. A reproduction characteristics of holstein cows raised at Ankara sugar factory farm. Türk Veterinerlikve Hayvancılık Dergisi. 1999;18(2):107-111.

6. Braun U, Trösch L, Nydegger F, et al. Evaluation of eating and rumination behaviour in cows using a noseband pressure sensor. BMC Veterinary Research. 2013;9:164.

7. Esslemont RJ. Economic and husbandry aspects of the manifestation of estrus in cows III. The detection of estrus. Adas Quarterly Review. $1974 ; 15: 83-95$.

8. Appleyard WT, Cook B. The detection of estrus in dairy cattle. The Veterinary Record. 1976;99(13):253-256.

9. Hoffmann B, Günzler O, Hamburger R, et al. Milk progesterone as a parameter for fertility control in cattle; methodological approaches and present status of application in Germany. The British Veterinary Journal. 1976;132(5):469-476

10. Galiç A, Baydilli T, Özfiliz A, et al. The effect of herd size on milk yield and reproduction traits in holstein cattle raised in İzmir province. Hayvansal Üretim. 2004;45(2):17-22.

11. Schofield SA, Phillips CJC, Owens AR. Variation in milk production, activity rate and electrical impedance of cervical mucus over the oestrus period of dairy cows. Animal Reproduction Science. 1991;24(3-4):231248

12. Grunert E. Fertilitätsstörungenbeimweiblichen Rind. In: Grunert E, Berchtold M, editors. Berlin: Blackwell; 1995.

13. Firk R, Stamer E, Junge W, et al. Automation of oestrus detection in dairy cows: A review. Livestock Production Science. 2002;75(3):219-232.

14. Roelofs JB, van Erp-van der Kooij E. Estrus detection tools and their applicability in cattle: recent and perspectival situation. Anim Reprod. 2015;12(3):498-504

15. Diskin M, Sreenan J. Expression and detection of oestrus in cattle. Reprod Nutr Dev. 2000;40(5):481-491.

16. Trimberger GW. Breeding efficiency in dairy cattle from artificial insemination at various intervals before and after ovulation. Nebr Agric Exp Sta Res Bull. 1948;153:3-25.

17. Arazi A, Pinsky N, Halachm I, et al. Current and near term technologies fo automated recording of animal data for precision dairy farming. Journal of Animal Science. 2007;86:377-377.

18. Neri G. First fifty years of chemoresistive gas sensors. Chemosensors 2015;3:1-20.
19. Roelofs JB, López-Gatius F, Hunter RHF, et al. When is a cow in estrus? Clinical and practical aspects. Theriogenology. 2010;74(3):327-344.

20. Ayalon N, Weis Y. The influence of a teaser bull on oestrus detection Refuah Veterinarith. 1970;27:22-25.

21. Kiddy CA. Variation in physical activity as an indication of estrus in dairy cows. J Dairy Sci. 1977;60 (1977):235-243.

22. Lpez-Gatius F, Santolaria P, Mundet I, et al. Walking activity at estrus and subsequent fertility in dairy cows. Theriogenology. 2005;63(5):1419-1429.

23. At-Taras EE, Spahr SL. Electronic detection of estrus in dairy cattle. 1998.

24. Watanabe T, Sakurai A, Kitazaki K. Dairy cattle monitoring using wireless acceleration-sensor networks. (C)//Proceedings of IEEE Sensors Lecce:(s.n.). 2008:526-529.

25. Jónssona R, Blankea M, Poulsenb NK, et al. Oestrus detection in dairy cows from activity and lying data using on-line individual models. Computers and Electronics in Agriculture. 2011;76(1):6-15.

26. Lee J, Zuo S, Chung Y, et al. Formant based acoustic features for cow's estrus detection in audio surveillance system. Advanced Video and Signal Based Surveillance (AVSS), 11th IEEE International Conference. 2014:236-240.

27. Choi D, Kim H, Chung Y, et al. Automatic detection of cattle mounting using motion and color information. 3rd International Conference on Computational Techniques and Artificial Intelligence (ICCTAI'2014) Feb. 11-12, 2014 Singapore. 2014:22-25.

28. Chung Y, Lee J, Oh S, et al. Automatic detection of cow's oestrus in audio surveillance system. Asian Australas J Anim Sci. 2013;26(7):1030-1037.

29. Gardner JW, Bartlett Philip N. Electronic noses: principles and applications. Oxford, New York: Oxford University Press; 1999.

30. Domenech A, Pich S, Aris A, et al. Heat identification by $17 \beta$-estradiol and progesterone quantification in individual raw milk sample by enzyme immunoassay. Electronic Journal of Biotechnology. 2011;14(4).

31. Weigerinck W, Setkus A, Buda V, et al. BOVINOSE pheromone-based sensor system for detecting estrus in dairy cows. Procedia Computer Science. 2011;7:340-342.

32. Fischer-Tenhagen $\mathrm{C}$, Wetterholm L, Tenhagen B, et al. Training dogs on a scent platform for oestrus detection in cows. Applied animal Behaviour Science. 2011;131(1-2):63-70.

33. Crowe MA, Hostens M, Opsomer G. Reproductive management in dairy cows -the future. Ir Vet J. 2018;71:1.

34. Anonymous. Guide to automated heat detection technologies. 2017

35. Jegadeesan S, Venkatesan GKD. Distant biometry in cattle farm using wireless sensor networks. 2016:1-5.

36. Kornmatitsuk B, Thitaram C, Kornmatitsuk S. Measurement of faecal progesterone metabolites and its application for early screening of open cows post-insemination. Reproduction in Domestic Animals. 2007;42(3):238-242.

37. Krishnai T, Rao S, Kumar N, et al. Heat detection techniques in cattle and buffalo. Vet World. 2013;6(6):363-369. 